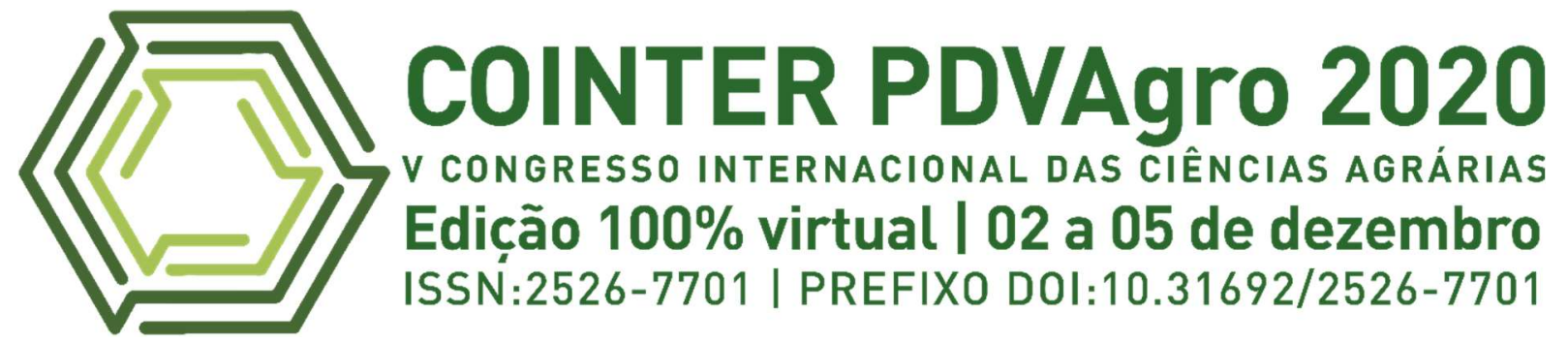

\title{
ANÁLISES QUANTITATIVAS DO CAPIM-TAMANI SOB DIFERENTES MANEJOS DA ADUBAÇÃO NITROGENADA
}

\section{ANÁLISES CUANTITATIVAS DEL PASTO TAMANI BAJO DIFERENTES GESTIONES DE FERTILIZACIÓN NITROGENADA \\ QUANTITATIVE ANALYSIS OF TAMANI GRASS UNDER DIFFERENT MANAGEMENT OF NITROGENATED FERTILIZATION}

\author{
Apresentação: Comunicação Oral \\ Vitória Gomes Damasceno ${ }^{1}$; Iuri de Almeida Moraes²; Milena Alves do Santos ${ }^{3}$; Juvenaldo Florentino \\ Canjá ${ }^{4}$; Magno José Duarte Cândido 5
}

DOI: https://doi.org/10.31692/2526-7701.VCOINTERPDVAgro.0456

\begin{abstract}
RESUMO
O Brasil é o segundo maior produtor e o maior exportador de carne bovina do mundo possuindo milhões de hectares de pastagens. Diante disso, a adubação nitrogenada é de fundamental importância no manejo dessas áreas, uma vez que esse nutriente é considerado o fator limitante no crescimento das plantas forrageiras. Assim, objetivou-se avaliar parâmetros quantitativos de capim-tamani submetido a diferentes manejos da adubação nitrogenada. O experimento foi conduzido no Núcleo de Ensino e Estudos em Forragicultura -NEEF/DZ/CCA/UFC, pertencente à Universidade Federal do Ceará. Adotou-se um delineamento em blocos casualizados com seis tratamentos e quatro repetições, totalizando 24 unidades experimentais. Os tratamentos consistiram de diferentes parcelamentos de ureia de liberação controlada (a cada 365 dias; a cada 182 dias; a cada 91 dias e a cada 61 dias, correspondendo a 1; 2; 4 e 6 aplicações por ano respectivamente), de ureia convencional e o tratamento controle (sem adubação nitrogenada). A altura do dossel (AD) foi estimada medindo-se a altura do pasto em 30 pontos, utilizando-se um bastão graduado retrátil. A densidade populacional de perfilhos (DPP) foi estimada contando-se os perfilhos vivos dentro de uma moldura de $0,50 \times 0,50 \mathrm{~m}$, em duas amostras dentro da unidade experimental. As biomassas de forragem total e colhível foram estimadas cortando-se, em cada unidade experimental, duas amostras de $0,50 \times 0,50 \mathrm{~m}$ a uma altura de $16 \mathrm{~cm}$ acima da superfície do solo. Os dados foram submetidos à análise de variância, teste comparação de médias e análise de regressão pelo programa computacional SAS. Também foram calculados coeficientes de correlação de Pearson. Houve efeito significativo $(\mathrm{P}<0,05)$ apenas para as variáveis taxa de produção de forragem (TPF) e taxa de acúmulo de forragem (TAF), quando comparados aos tratamentos controle (sem nitrogênio) e com uréia. Os tratamentos em que foram estudados os diferentes parcelamentos do adubo de liberação controlada não diferiram entre si. A aplicação de fertilizante comercial de liberação controlada no tratamento Polyblen 1x (aplicação única) apresenta resultados estatisticamente iguais às aplicações parceladas para as variáveis TAF, TPF, AD e DPP em capim-tamani. Recomenda-se a

\footnotetext{
${ }^{1}$ Graduanda em Agronomia, Universidade Federal do Ceará, vitoriadamascenoagro@gmail.com

${ }^{2}$ Graduando em Zootecnia, Universidade Federal do Ceará, iuriamoraes@gmail.com

${ }^{3}$ Mestranda em Zootecnia, Universidade Federal do Ceará, milenaalvessanto@outlook.com

${ }^{4}$ Mestrando em Engenharia Agrícola, Universidade Federal do Ceará, batchijuve@gmail.com

${ }_{5}^{5}$ Professor do Departamento de Zootecnia, Universidade Federal do Ceará, magno@ufc.com
} 
aplicação da ureia de liberação controlada em aplicação única. As variáveis quantitativas, em especial a densidade populacional de perfilhos, ajudaram na avaliação da pastagem, permitindo observar as respostas da gramínea ao manejo que lhe foi empregado.

Palavras-Chave: acúmulo de forragem, adubos de liberação controlada, avaliações estruturais, Megathyrsus maximus cv. BRS Tamani.

\section{RESUMEN}

Brasil es el segundo productor y exportador de carne vacuna del mundo, con millones de hectáreas de pastos. Por lo tanto, la fertilización con nitrógeno es de fundamental importancia en el manejo de estas áreas, ya que este nutriente es considerado el factor limitante en el crecimiento de plantas forrajeras. Así, el objetivo de este trabajo fue evaluar parámetros de altura de copa $(\mathrm{cm})$, densidad poblacional de macollos (perf.ha-1) y tasas de producción y acumulación de biomasa forrajera (kg.ha-1.dia-1.MS ) en pasto Tamani sometido a diferentes manejos de fertilización con nitrógeno. El experimento se realizó en el Centro de Docencia y Estudios en Cultivo Forrajero - NEEF / DZ / CCA / UFC, perteneciente a la Universidad Federal de Ceará. Se adoptó un diseño de bloques al azar con seis tratamientos y cuatro repeticiones, totalizando 24 unidades experimentales. Los tratamientos consistieron en diferentes cuotas de urea de liberación controlada (cada 365 días; cada 182 días; cada 91 días y cada 61 días, correspondientes a 1;2; 4 y 6 aplicaciones por año respectivamente), de urea convencional y el tratamiento de control (sin fertilización nitrogenada). La altura del dosel (AD) se estimó midiendo la altura del pasto en 30 puntos, usando una vara graduada retráctil. La densidad de población de macollos (DPP) se estimó contando macollos vivos dentro de un marco de $0.50 \times 0.50 \mathrm{~m}$, en dos muestras dentro de la unidad experimental. Las biomasas forrajeras totales y cosechables se estimaron cortando, en cada unidad experimental, dos muestras de $0.50 \times 0.50 \mathrm{~m}$ a una altura de $16 \mathrm{~cm}$ sobre la superficie del suelo. Los datos fueron sometidos a análisis de varianza, prueba de comparación de medias y análisis de regresión por el programa informático SAS. También se calcularon los coeficientes de correlación de Pearson. Hubo un efecto significativo $(\mathrm{P}<0.05)$ solo para las variables tasa de producción de forraje (TPF) y tasa de acumulación de forraje (TAF), cuando se compararon con los tratamientos control (sin nitrógeno) y con urea. Los tratamientos en los que se estudiaron las diferentes entregas del fertilizante de liberación controlada no difirieron. La aplicación de fertilizante comercial de liberación controlada en el tratamiento Polyblen 1x (aplicación única) presenta resultados estadísticamente iguales a las aplicaciones divididas para las variables TAF, TPF, AD y DPP en pasto Tamani. Se recomienda la aplicación de urea de liberación controlada en una sola aplicación. Las variables cuantitativas, especialmente la densidad poblacional de macollos, ayudaron en la evaluación del pasto, permitiendo observar las respuestas del pasto al manejo que se utilizó.

Palabras Clave: acumulación de forraje, evaluaciones estructurales, fertilizantes de liberación controlada, Megathyrsus maximus cv. BRS Tamani.

\section{ABSTRACT}

Brazil is the second largest producer and exporter of beef in the world, with millions of hectares of pasture. That said, nitrogen fertilization is of fundamental importance in the management of these areas, since this nutrient is considered the limiting factor in the growth of forage plants. Thus, the objective of this work was to evaluate parameters of canopy height $(\mathrm{cm})$, tiller population density (perf.ha-1) and production rates and accumulation of forage biomass (kg.ha-1.dia-1.MS ) in Tamani grass submitted to different nitrogen fertilization management. The experiment was conducted at the Center for Teaching and Studies in Forage Culture - NEEF / DZ / CCA / UFC, belonging to the Federal University of Ceará. A randomized block design with six treatments and four replications was adopted, totaling 24 experimental units. The treatments consisted of different installments of controlled-release urea (every 365 days; every 182 days; every 91 days and every 61 days, corresponding to 1;2; 4 and 6 applications per year respectively), of conventional urea and the control treatment (without nitrogen fertilization). The height of the canopy (AD) was estimated by measuring the height of the pasture at 30 points, using a retractable graduated stick. Tiller population density (DPP) was estimated by counting live tillers within a $0.50 \times 0.50 \mathrm{~m}$ frame, in two samples within the experimental unit. The total and harvestable forage biomasses were estimated by cutting, in each experimental unit, two samples of $0.50 \times 0.50 \mathrm{~m}$ at a height of $16 \mathrm{~cm}$ above the soil surface. The data were submitted to analysis of variance, test of comparison of means and regression analysis by the computer program SAS. Pearson's correlation 
coefficients were also calculated. There was a significant effect $(\mathrm{P}<0.05)$ only for the forage production rate (TPF) and forage accumulation rate (TAF) variables, when compared to the control treatments (without nitrogen) and with urea. The treatments in which the different installments of the controlledrelease fertilizer were studied did not differ. The application of controlled-release commercial fertilizer in the Polyblen $1 \mathrm{x}$ treatment (single application) presents statistically equal results to the split applications for the variables TAF, TPF, AD and DPP in Tamani grass. The application of controlledrelease urea in a single application is recommended. The quantitative variables, especially the population density of tillers, helped in the evaluation of the pasture, allowing to observe the responses of the grass to the management that was used.

Keywords: controlled-release fertilizers, forage accumulation, Megathyrsus maximus cv. BRS Tamani, structural assessments.

\section{INTRODUÇÃO}

As características edafoclimáticas e a extensão territorial fazem do Brasil um país de vocação natural para a atividade pecuária, sendo as pastagens a principal fonte de alimento dos rebanhos comerciais, proporcionando baixo custo de produção (DEBLITZ, 2012). Dados da Organização das Nações Unidas (GERLAND et al., 2014) prospectam um crescimento populacional mundial que poderá atingir 9,6 bilhões de habitantes em 2050, causando impacto direto na produção e consumo de alimentos de origem animal. Estima-se que o Brasil possui atualmente cerca de 196 milhões de hectares de pastagens (FAOSTAT, 2013), sendo aproximadamente 100 milhões de hectares constituídos de pastagens cultivadas, que por sua vez são ocupadas por cerca de 214 milhões de bovinos, 18 milhões de ovinos e 9 milhões de caprinos (DIAS FILHO, 2014; IBGE 2018; SANTOS et al., 2011).

Atualmente, o Brasil é o segundo maior produtor e o maior exportador de carne bovina do mundo (ABIEC, 2018), sendo essa produção baseada principalmente em sistemas que utilizam a pastagem como alternativa mais economicamente viável se comparada com a produção em confinamento (DIAS FILHO, 2014). O aumento na produtividade de carne e leite no Brasil deve-se, principalmente, à adoção de novas tecnologias pelos pecuaristas, incluindo a utilização de novas forrageiras mais responsivas em sistemas intensivos de produção, lançadas pelos centros de pesquisas (MARTUSCELLO et al., 2007). A alta produtividade dessas pastagens também está relacionada ao desenvolvimento de forrageiras mais adaptadas, destinadas à produção de alimento para animais em pastejo (LOPES et al., 2014).

Sistemas de produção a pasto são caracterizados pela demanda de genótipos melhorados e insumos que os tornem mais eficientes, competitivos e lucrativos, frente aos desafios da produção pecuária. Nesse contexto, as gramíneas do gênero Megathyrsus (syn. Panicum) ocupam a maior parte das áreas de pastagens cultivada, devido a características como boa produção de forragem, boa adaptação ao clima, facilidade de estabelecimento, persistência, bom valor nutritivo, baixa suscetibilidade a doenças e pragas e bom crescimento durante a maior 


\section{ANÁLISES QUANTITATIVAS DO CAPIM-TAMANI}

parte do ano, fazendo com que os capins desse gênero sejam muito populares entre os pecuaristas (COSTA et al., 2005).

A cultivar BRS Tamani (Megathyrsus maximus cv. BRS Tamani) foi o primeiro híbrido lançado pela Embrapa, oriundo do cruzamento entre a planta sexual S12 e o acesso apomítico T60 (BRA-007234). Possui elevado potencial de produção de biomassa, flexibilidade aos possíveis erros de manejo e adaptação as condições edafoclimáticas das regiões tropicais. Essa forrageira foi lançada no mercado com a pretensão de maximizar as características até então não alcançadas pelo capim-massai. É altamente responsiva à adubação nitrogenada para a produção de alimento para o rebanho. Possui porte baixo e fácil manejo em sistemas intensivos, tornando-se ideal para a alimentação de ovinos, caprinos e bovinos (EMBRAPA, 2015).

O nitrogênio propicia respostas positivas sobre o crescimento e desenvolvimento de plantas, sendo o nutriente que mais limita o crescimento de plantas forrageiras (CHAPIN et al., 1987), tornando a adubação nitrogenada uma ferramenta de grande importância para que altos níveis de produção de forragem sejam alcançados, uma vez que a disponibilidade de nitrogênio favorece o crescimento e o desenvolvimento da planta, sendo o principal componente das proteínas, atuando na biossíntese e na formação da matéria orgânica que compõe a estrutura vegetal, auxiliando na formação de novas gemas axilares e de novos perfilhos (TOMASZEWSKA et al., 2002).

Adubos com a tecnologia de liberação controlada dos nutrientes apresentam resposta positiva devido apresentarem alta praticidade de aplicação, por sua vez, acarretando uma maior eficiência em seu uso e diminuindo o número de aplicações durante o ano, permitindo também uma menor ida ao campo. Contudo, estudos que mostram a viabilidade prática e econômica desses adubos ainda são escassos.

Dessa forma, objetivou-se avaliar parâmetros quantitativos de capim-tamani submetido a diferentes manejos da adubação nitrogenada.

\section{FUNDAMENTAÇÃO TEÓRICA}

\section{Adubação nitrogenada}

O manejo de pastagens baseado na adubação nitrogenada apresenta-se como uma prática fortemente indicada para forrageiras exigentes nutricionalmente e com alta produção de biomassa de forragem (PARIS et al., 2009; VITOR et al., 2009). A maioria das gramíneas tropicais tendem à responsividade da adubação mineral, com maior produção de forragem de melhor valor nutritivo em detrimento as concentrações desse nutriente aplicado (COSTA et al., 2009; VIANA et al., 2011). 
Adubos nitrogenados garantem um incremento na produção de forragem, principalmente em pastagens sob manejo intensivo (PRIMAVESI et al., 2001). Para forrageiras tropicais, a recomendação de adubação nitrogenada varia em doses equivalentes a 400 a $600 \mathrm{~kg}$ $\mathrm{ha}^{-1} \mathrm{ano}^{-1}$, potencializando a produção de forragem das forrageiras (MARTHA JÚNIOR et al., 2004). Corsi e Nussio (1992), ainda afirmam que existe a possibilidade de resposta ainda mais elevada à adubação nitrogenada entre a faixa de 400 a $800 \mathrm{~kg}$ ha-1, com eficiência de conversão que pode variar entre 40 a $70 \mathrm{~kg}$ de MS por $\mathrm{kg}$ de nitrogênio aplicado.

Rodrigues et al. (2005), trabalhando com Pennisetum purpureum cv. pioneiro; Megathyrsus maximus cv. tanzânia e Cynodon sp cv. tifton-85 adubados com ureia nas doses de 100, 200 e $300 \mathrm{~kg}$ de $\mathrm{N} \mathrm{ha}^{-1}$ observaram que na dose de $200 \mathrm{~kg}_{\text {de }} \mathrm{N} \mathrm{ha}^{-1}$, o capim-tanzânia produziu 24,984 $\mathrm{kg} \mathrm{ha}^{-1}$. noo $^{-1}$ de matéria seca, sobrasaindo-se às demais doses aplicadas. Martuscello et al. (2015), avaliando doses de 0, 80, 160 e $240 \mathrm{~kg}$ de $\mathrm{N} \mathrm{ha}^{-1}$ em capim-massai, identificaram que conforme a adubação aumenta de 0 até $240 \mathrm{~kg}$, a forrageira avaliada responde através do incremento na matéria seca.

Gramíneas que possuem elevado potencial produtivo tendem a exigir elevadas quantidades de nutrientes do solo, tornando necessária a resposição desses nutrientes em proporções adequadas (PRIMAVERSI, 2004; COSTA et al., 2010). Costa et al. (2010) estudando duas cultivares de Urochloa brizantha sob quatro doses de nitrogênio que correspondiam a $0,50,100$ e $150 \mathrm{mg} \mathrm{dm}^{-3}$ obtiveram aumento linear na exportação de nitrogênio, fósforo, potássio, magnésio e enxofre nas respectivas porcentagens $70 \%, 48 \%, 36 \%$, $10,9 \%$ e $91 \%$ em relação ao tratamento controle, e o cálcio não foi influenciado pelas doses. Esses resultados evidenciam que a exportação de nutrientes dependerá do solo que está sendo manejo, da exigência nutricional da planta durante os ciclos de cultivos e da dose de nitrogênio fornecido, revelando ainda que espécies mais jovens tendem a exigir mais nutrientes do solo (PEREZ et al., 2013).

\section{Adubos de liberação controlada}

Os adubos de liberação controlada, atualmente podem ser definidos como aqueles nos quais são conhecidos os fatores que determinam o padrão, a quantidade e até mesmo a duração da liberação do nutriente para as plantas (SHAVIV, 2005).

De forma geral, esses adubos com liberação controlada propiciam um maior controle em relação a duração, padrão, e principalmente sobre a taxa de liberação de nutrientes, permitindo assim, uma maior eficiencia e minimizando impactos ambientais (SHAVIV, 2005). Uma vez que, esses adubos são menos sensíveis a fatores ambientais e de solo, quando comparados com outros adubos nirogenados (VILLALBA, 2014). 
Como estratégia para minimizar as perdas de nitrogênio, vem sendo adotada a aplicação dos adubos de liberação controlada. Tal estratégia permite uma diminuição nas perdas de amônia por volatilização, por meio de inibidores enzimáticos, de compostos orgânicos sintéticos não revestidos (PEREIRA et al., 2009).

Os inibidores enzimáticos atuam ocupando o sítio ativo da enzima urease, que é responsável pela hidrólise da molécula (PEREIRA et al., 2009). Okumura e Mariano (2012) observaram que com o atraso da hidrólise da ureia a concentração de amônia próxima à superfície do solo e a volatilização são reduzidas, melhorando assim a incorporação da ureia no perfil do solo pela chuva.

A melhor eficiência de utilização dos fertilizantes protegidos se dá pela estrutura dos grânulos, esses ao absorverem água do solo, solubilizam os nutrientes no interior das cápsulas, liberando lentamente pela estrutura porosa e atingindo a região da raiz da planta (GUARESCHI et al., 2011).

Quando as raízes absorvem os nutrientes, acaba ocorrendo uma perda na concentração dos mesmos, nas proximidades da zona radicular, desencadeando um sistema de liberação de nutrientes por osmose (TOMASZEWSKA et al., 2002).

A utilização de adubos de liberação controlada permite um decréscimo nos gastos com mão de obra com a aplicação de fertilizantes, ressaltando que para determinadas espécies, é necessário apenas a mistura deste adubo ao substrato (PEREIRA et al., 2000; LANA et al., 2002; SERRANO et al., 2006).

As principais vantagens do uso de ureia protegida são: fornecimento regular e constante do N para a planta, redução das perdas por lixiviação e/ou volatilização, redução na poluição ambiental pelo nitrato $\left(\mathrm{NO}_{3}\right)$ e redução no acúmulo de sais no solo (SHAVIV, 2011).

\section{Megathyrsus maximus cv. BRS Tamani}

A adoção de forrageiras exóticas do gênero Megathyrsus no Brasil vem sendo bastante difundida e indicada para sistemas intensivos sob pastejo, devido a características como boa capacidade produtiva e grandes quantidades de biomassa (POMPEU et al., 2010; LOPES et al., 2014). Gramíneas desse gênero são bem exploradas na pecuária, sendo estimadas por sua boa adaptação aos climas tropicais e subtropicais (GOMES et al., 2011), fácil propagação através de sementes e bom rendimento de matéria verde por hectare, tornando-as espécies bastante difundidas pelos produtores. As mais utilizadas atualmente são capim-massai, capim-mombaça e capim-tanzânia (VALENTIM et al., 2001; JANK et al., 2013).

O capim-tamani, pertencente ao gênero Megathyrsus, foi lançado em 2015 pela Embrapa (Empresa Brasileira de Pesquisa Agropecuária), e foi obtido através do cruzamento 
entre a planta sexual S12 e o acesso apomítico T60 (BRA-007234), realizado na Embrapa Gado de Corte em 1992, com o apoio da UNIPASTO (Associação para Fomento à Pesquisa de Melhoramento de Forrageiras). Tamani significa "Precioso" em suaíli, língua adotada no Quênia. Foi registrada no ano de 2014 e protegida em 2015 pelo Ministério da Agricultura, Pecuária e Abastecimento (EMBRAPA, 2016).

A cv. BRS Tamani é um híbrido considerado altamente promissor na alimentação animal. Possui hábito de crescimento cespitoso, apresentando colmos finos e sem pilosidade. É uma forrageira ideal para o pastejo por bovinos e ovinos em sistemas intensivos devido ao seu porte intermediário (TESK et al., 2017). Avaliações de produtividade dessa gramínea resultaram, apenas de matéria seca foliar, cerca de $15 \mathrm{mil} \mathrm{kg} \mathrm{ha}^{-1}$.ano ${ }^{-1}$. Observou-se também que a cultivar apresenta 9\% mais proteína bruta quando comparada a cv. Tanzânia, sendo considerada mais digestível (EMBRAPA, 2015). As principais características morfofisiológicas são o porte baixo, alta produção de folhas de alto valor nutritivo (elevados teores de proteína bruta e digestibilidade), produtividade e vigor, e resistência às cigarrinhas das pastagens. É indicada para engorda de bovinos devido a sua alta qualidade e adaptação (GAVALI, 2016).

\section{$\underline{\text { Avaliações estruturais e produtividade }}$}

Dentre as características estruturais das gramíneas forrageiras, a altura do dossel é considerada uma variável de fácil mensuração, consiste em uma primeira aproximação da quantidade de forragem presente numa determinada área. Para os animais, a altura representa quantidade de biomassa presente (LACA et al., 1992).

Apesar de muitas vezes a altura ser utilizada como indicador de produção por alguns autores, Barthram (1981) afirmou que a altura do dossel não é o índice ideal para estimativa de produção de forragem, visto que a altura do pseudocolmo pode superestimar a disponibilidade de forragem colhível, uma vez que as folhas são as partes preferíveis pelos animais. Por sua vez, Stobbs (1973) afirmou também que nos pastos tropicais, notase uma redução da densidade de forragem com a elevação da altura, comprovando desta maneira, que não há uma relação direta entre altura e biomassa de forragem.

Desta forma, para gramíneas do tipo $\mathrm{C} 4$, a altura do dossel pode comprometer o valor nutritivo da forragem. Isso é devido ao alongamento do pseudocolmo, que por sua vez eleva as frações de carboidratos estruturais da parede celular vegetal, principalmente lignina, que pode reduzir os valores de proteína bruta e o consumo devido à redução da ingestão de matéria seca. Com isso, pode haver aumento no tempo de pastejo em virtude da diminuição do tamanho de bocados (POMPEU et al., 2008). 
Por sua vez, a densidade populacional de perfilhos (DPP) em uma população de plantas forrageiras é função do equilíbrio entre as taxas de aparecimento e morte dos perfilhos (LEMAIRE e CHAPMAN, 1996). No entanto, esse equilíbrio entre a taxa de aparecimento e morte dos perfilhos é estritamente dependente da desfolhação, o qual por sua vez determina a evolução do IAF. Desta forma, a taxa de surgimento potencial de perfilhos só pode ser atingida quando o IAF da pastagem é baixo, devido ao fato do surgimento de novos perfilhos decrescer à medida que ocorre o crescimento do IAF (NABINGER e PONTES, 2001).

A produção e o acúmulo de biomassa de forragem em plantas forrageiras é resultado das diversas interações complexas de atributos genéticos e de ambiente e seus efeitos sobre os processos fisiológicos e características morfológicas das plantas (DA SILVA; PEDREIRA, 1997).

\section{METODOLOGIA}

O experimento foi conduzido no Núcleo de Ensino e Estudos em Forragicultura NEEF/DZ/CCA/UFC, pertencente à Universidade Federal do Ceará. Os dados utilizados no presente estudo são preliminares e foram coletados no período de março a abril de 2020, durante a época chuvosa.

A cidade de Fortaleza, localiza-se na zona litorânea a 15,49 m, com latitude sul $03^{\circ} 45^{\prime} 47^{\prime \prime}$ e longitude oeste $38^{\circ} 31^{\prime} 23^{\prime}$ '. O clima da região é Aw', classificação dada por Köppen (1936), que se configura como tropical chuvoso com precipitações de verão. As médias anuais de temperatura do ar, pluviometria, evapotranspiração potencial e umidade relativa são respectivamente: $26,3{ }^{\circ} \mathrm{C} ; 1600 \mathrm{~mm} ; 3215 \mathrm{~mm} ; 62 \%$. O solo é classificado como Argissolo Amarelo Eutrófico Típico (EMBRAPA, 2006). A área experimental foi alocada em aproximadamente $300 \mathrm{~m}^{2}$, em uma área implementada há dois anos com cv. tamani, sendo subdividida em 24 parcelas de 12,5 $\mathrm{m}^{2}$ cada (Figura 01). 
Figura 01: Vista geral da área experimental.

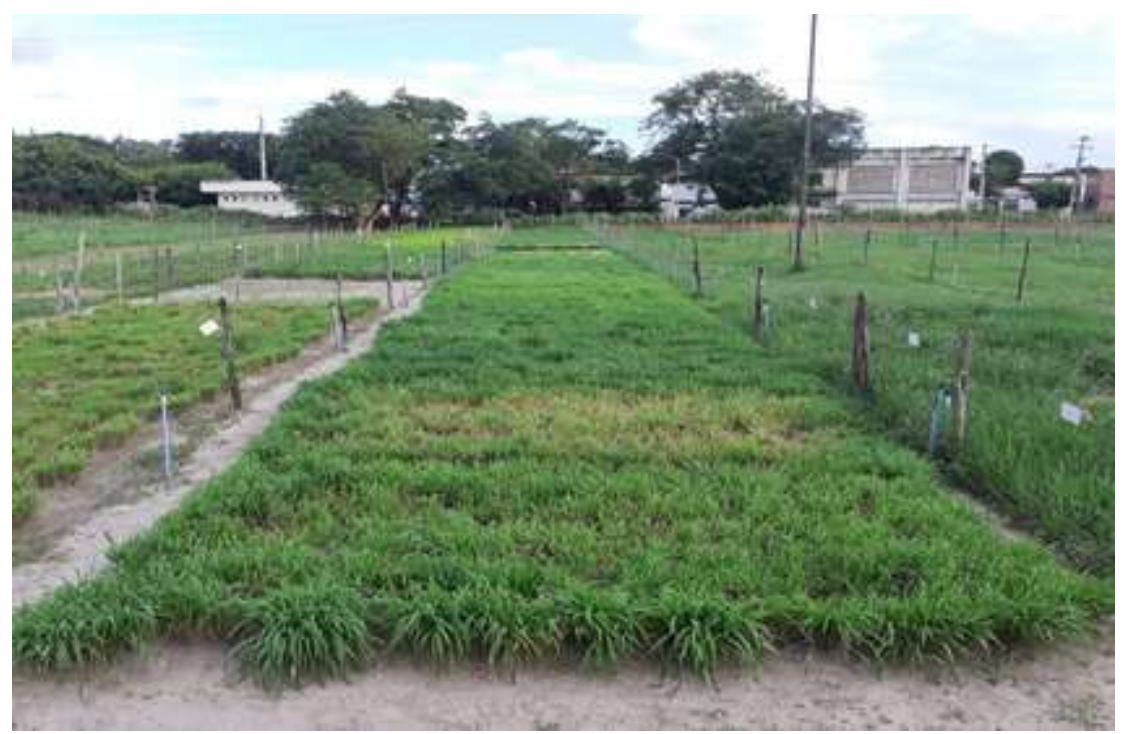

Fonte: SANTOS (2020).

Os dados climáticos do período experimental foram obtidos no Instituto Nacional de Meteorologia - INMET (2020) e estão apresentados na tabela 01.

Tabela 01: Precipitação (mm), temperatura $\left({ }^{\circ} \mathrm{C}\right)$ e umidade relativa do ar $(\%)$ durante o período experimental.

\begin{tabular}{cccc}
\hline & Precipitação & Temperatura & Umidade relativa \\
\hline Março & 68,40 & 27,61 & 78,26 \\
Abril & 139,80 & 27,72 & 79,87 \\
\hline Médias & 104,10 & 27,67 & 79,07 \\
\hline
\end{tabular}

Fonte: INMET (2020).

Adotou-se um delineamento em blocos casualizados com seis tratamentos e quatro repetições, totalizando 24 unidades experimentais.

Os tratamentos consistiram de diferentes parcelamentos de ureia de liberação controlada (a cada 365 dias; a cada 182 dias; a cada 91 dias e a cada 61 dias, correspondendo a 1;2; 4 e 6 aplicações por ano respectivamente), de ureia convencional e o tratamento controle (sem adubação nitrogenada). A dose de nitrogênio utilizada no presente estudo foi equivalente a 600 $\mathrm{kg} \mathrm{ha}^{-1}$. A ureia de liberação controlada utilizada, nome comercial Polyblen, foi desenvolvida pela Produquímica Indústria e Comércio S.A ${ }^{\circledR}$.

Antes do início do experimento coletaram-se amostras, na camada de $0-20 \mathrm{~cm}$ de profundidade, feito uma amostra composta e levada ao Laboratorio de Solos da Universidade Federal do Ceará para a determinação das características químicas do solo (Tabela 02). 
Tabela 02: Características químicas do solo da área experimental, na profundidade de 0 a $20 \mathrm{~cm}$. $\mathrm{P}$ - fósforo; $\mathrm{K}$ - potássio; $\mathrm{Ca}$ - cálcio; $\mathrm{Mg}$ - magnésio; $\mathrm{pH}$ - potencial hidrogeniônico; $\mathrm{Al}$ - alumínio; $\mathrm{SB}$ - soma de bases; CTC - capacidade de troca de cátions; M.O. - matéria orgânica.

\begin{tabular}{ccccccccc}
\hline $\begin{array}{c}\mathbf{p H} \\
\left(\mathrm{H}_{2} \mathrm{O}\right)\end{array}$ & $\begin{array}{c}\mathbf{M O} \\
\mathrm{g} \mathrm{dm}^{-3}\end{array}$ & $\begin{array}{c}\mathbf{P} \\
---\end{array} \mathrm{mg} \mathrm{dm}^{-3}-\mathbf{K}^{+}$ & $\mathbf{C a}^{\mathbf{2 +}}$ & $\mathbf{M g}^{\mathbf{2 +}}$ & $\mathbf{A l}^{3+}$ & $\mathbf{S B}$ & $\mathbf{C T C t}$ \\
\hline 6,8 & 7,5 & 21,0 & 70,4 & 1,1 & 0,3 & 0 & 1,9 & 2,4 \\
\hline Acidez fraca & Baixa & Médio & Médio & Baixo & Baixo & Baixo & Médio & Baixa \\
\hline \multicolumn{7}{c}{ Fonte: Própria (2020). } \\
\end{tabular}

A partir dos resultados da análise de solo, foi feita a recomendação de adubação para o capim com alto potencial produtivo e manejo de alto nível tecnológico (CFSEMG, 1999), com aplicações de manutenção/produção durante os ciclos de crescimento da forrageira durante o período experimental.

O corte de uniformização foi realizado a $10 \mathrm{~cm}$ de altura com o auxílio de uma roçadeira lateral (Figura 02 A e B). Em seguida foi feita a adubação de manutenção, segundo recomendações baseando-se na análise do solo, nas seguintes doses: $20 \mathrm{~kg} \mathrm{ha}^{-1}$ de $\mathrm{P}_{2} \mathrm{O}_{5}$, tendo como fonte o superfosfato simples, $100 \mathrm{~kg} \mathrm{ha}^{-1}$ de $\mathrm{K}_{2} \mathrm{O}$, usando-se o cloreto de potássio como fonte e $50 \mathrm{~kg} \mathrm{ha}^{-1}$ de FTE BR 12 como fonte de micronutrientes. A adubação com nitrogênio foi feita de acordo com os tratamentos preconizados. A dispersão dos fertilizantes foi feita a lanço (Figura $02 \mathrm{C}$ ).

Figura 02: Corte de uniformização do pasto a $10 \mathrm{~cm}$ acima do solo (A e B) e aplicação dos fertilizantes via lanço $(\mathrm{C})$.

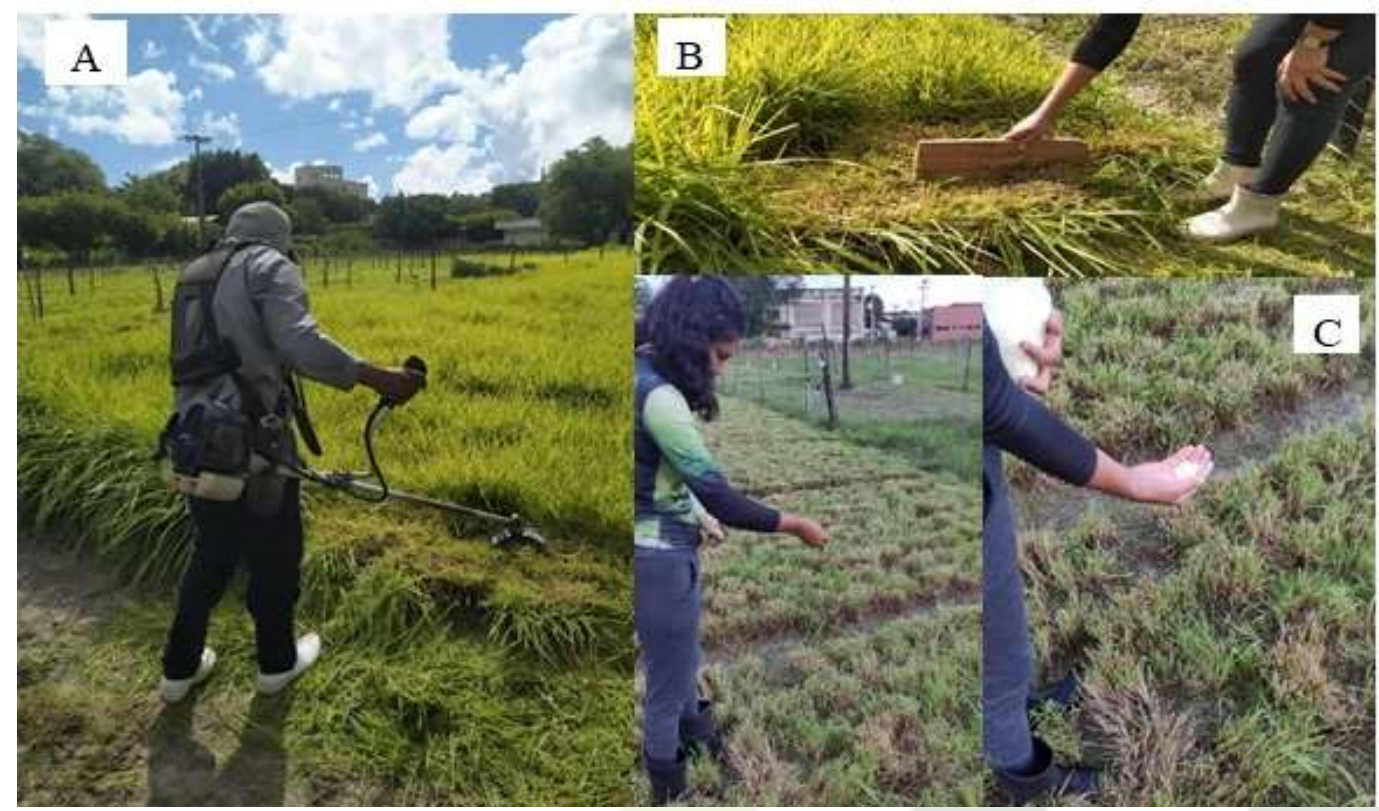

Fonte: SANTOS (2020).

A altura do dossel (AD), em cm, foi estimada medindo-se a altura do pasto em 30 pontos, utilizando-se um bastão graduado retrátil. A densidade populacional de perfilhos (DPP), em 
perf.ha ${ }^{-1}$, foi estimada contando-se os perfilhos vivos dentro de uma moldura de $0,50 \times 0,50 \mathrm{~m}$, em duas amostras dentro da unidade experimental. As biomassas de forragem total e colhível foram estimadas cortando-se, em cada unidade experimental, duas amostras de 0,50 x 0,50 m a uma altura de $16 \mathrm{~cm}$ acima da superfície do solo. As amostras foram pesadas, secas em estufa de ventilação forçada a $55^{\circ} \mathrm{C}$ até atingir peso constante e pesadas novamente. De posse desses dados e do período de descanso (28 dias), estimou-se as taxas de produção e acúmulo de biomassa de forragem, em kg.ha ${ }^{-1} \cdot \mathrm{dia}^{-1}$.MS, para cada tratamento. Para a taxa de produção, dividiu-se a biomassa seca de forragem total pelo período de descanso, e para a taxa de acúmulo, dividiu-se a biomassa seca de forragem colhível pelo mesmo período.

Os dados foram submetidos à análise de variância e teste comparação de médias. As médias foram comparadas pelo teste de Tukey, ao nível de 5\% de probabilidade. Como ferramenta de auxílio a análise estatística foi utilizado o procedimento GLM, do programa computacional SAS (SAS INSTITUTE, 2003).

Além disso, foram calculados os coeficientes de correlação de Pearson (r), cujos valores variam de -1 a 1 e sugerem a força da relação entre as variáveis. Uma correlação perfeitamente positiva entre duas variáveis é representada por valores próximos a $1(\mathrm{r}=1)$, enquanto uma correlação perfeitamente negativa é representada por valores próximos a $-1(\mathrm{r}=-1)$, indicando que quando uma variável aumenta, a outra diminui. Dancey \& Reidy (2006) propuseram uma classificação para o coeficiente de correlação de Pearson em $r=0,10$ a 0,30 (fraco), $r=0,40$ a 0,6 (moderado) e r = 0,70 a 1 (forte). Segundo Figueiredo Filho \& Silva Júnior (2009), o grau de dependência estatística linear entre as variáveis é maior quando o valor está mais próximo de 1 (independente do sinal), mas a força dessa relação é menor quando o valor está mais próximo de zero.

As variáveis que apresentaram valores de correlação próximos a 1 foram submetidas a análise de regressão com o intuito de encontrar a regressão que mais se adequava à correlação. Os dados foram utilizados para confecção dos gráficos de relação entre as variáveis, utilizando o programa Microsoft Excel 2016.

\section{RESULTADOS E DISCUSSÃO}

Houve efeito significativo $(\mathrm{P}<0,05)$ apenas para as variáveis taxa de produção de forragem (TPF) e taxa de acúmulo de forragem (TAF), quando comparados os tratamentos controle (sem nitrogênio) e com uréia. Os tratamentos em que foram estudados os diferentes parcelamentos do Polyblen não diferiram entre si. Isso pode ser explicado devido ao recobrimento do fertilizante, que gera diferenciação na dinâmica de liberação do nutriente, 
existindo a possibilidade do fornecimento do $\mathrm{N}$ da ureia em sincronia com o crescimento da cultura. Nesse contexto, torna-se possível providenciar o elemento de forma suficiente em aplicação única atendendo as necessidades nutricionais da planta e, ainda, conservar baixas as concentrações de $\mathrm{N}$ mineral nos solos durante toda temporada de crescimento (PEOPLES; FRENEY; MOSIER, 1995; GAO et al., 2015).

O possível efeito resultante desta maior otimização do uso do nutriente pela gramínea estudada é a redução de perdas para o ambiente, tornando possíveis reduções nas perdas por lixiviação, desnitrificação, imobilização e volatilização (SHAVIV, 2001). Além disso, também poderá ocorrer minimização dos gastos com mecanização, já que com uma única aplicação elimina-se a reentrada de máquinas e implementos na área para distribuição do fertilizante, o que diminui, também, a emissão de gases do efeito estufa resultantes da queima de combustíveis fosseis para a atmosfera.

O tratamento controle (sem nitrogênio) apresentou as menores taxas de produção e acúmulo de forragem. Essa diminuição na produtividade é bem conhecida na ausência do fornecimento de nitrogênio, reforçando que solos responsivos à adubação nitrogenada, na ausência desta, apresentam valores de baixa produtividade (MARTINS, 2013; VILLALBA, 2014).

A utilização de adubos nitrogenados de liberação controlada tem sido muito estudada em culturas como o milho. Trabalhos como o de Guareschi, Perin e Gazolla (2013) vem mostrando vantagens na utilização destes produtos frente ao uso da ureia convencional no fator produtividade. Tem-se, também, resultados positivos na utilização dos fertilizantes de liberação controlada aplicados às mais variadas culturas como algodão (GENG et al., 2016), arroz (YANG et al., 2012) e batata (GAO et al., 2015), o que revela uma necessidade de abordagens mais específicas do estudo desse fertilizante em gramíneas.

Tabela 03: Taxas de produção e acúmulo de forragem, densidade populacional de perfilhos e altura do dossel.

\begin{tabular}{|c|c|c|c|c|}
\hline \multirow{3}{*}{ Tratamentos } & \multicolumn{4}{|c|}{ Variáveis analisadas } \\
\hline & TPF & TAF & \multirow{2}{*}{$\begin{array}{c}\text { DPP } \\
\text { perf.ha }{ }^{-1}\end{array}$} & \multirow{2}{*}{$\begin{array}{c}\mathrm{AD} \\
(\mathrm{cm})\end{array}$} \\
\hline & \multicolumn{2}{|c|}{ 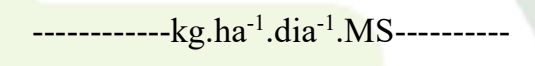 } & & \\
\hline Uréia & $110,05 \mathrm{AB}$ & $105,18 \mathrm{AB}$ & 1960,00 & 29,50 \\
\hline Polyblen 1x & $150,13 \mathrm{~A}$ & $129,12 \mathrm{~A}$ & 2032,00 & 30,74 \\
\hline Polyblen $2 \mathrm{x}$ & $152,77 \mathrm{~A}$ & $133,03 \mathrm{~A}$ & 2364,00 & 30,89 \\
\hline Polyblen 4x & $158,60 \mathrm{~A}$ & $141,81 \mathrm{~A}$ & 2236,00 & 31,41 \\
\hline Polyblen $6 x$ & $158,25 \mathrm{~A}$ & $148,55 \mathrm{~A}$ & 2472,00 & 31,79 \\
\hline Sem nitrogênio & $75,81 \mathrm{~B}$ & $72,02 \mathrm{~B}$ & 1944,00 & 32,50 \\
\hline Média & 132,07 & 119,48 & 2168,00 & 31,14 \\
\hline
\end{tabular}




\begin{tabular}{ccccc}
\hline $\mathrm{CV}(\%)$ & 19,89 & 17,71 & 12,09 & 8,89 \\
\hline
\end{tabular}

Médias seguidas da mesma letra não deiferem $(\mathrm{P}<0,05)$ entre si pelo teste de Tukey ao nível de $5 \%$ de probabilidade.

Fonte: Própia (2020).

As variáveis Densidade Populacional de Perfilhos (DPP) e Altura do Dossel (AD) não apresentaram efeito significativo entre os tratamentos, estando em faixas de valores semelhantes.

Vale ressaltar que os menores valores de DPP foram evidenciados no tratamento controle, corroborando com resultados de Vasconcelos (2014), que afirmam como a dinâmica de perfilhamento é influenciada pelo $\mathrm{N}$ disponível no solo. O contínuo surgimento de perfilhos e sua capacidade de manutenção ao longo do tempo garantem a persistência do pasto durante os ciclos de pastejo. A produção de novos perfilhos é um processo contínuo, podendo ser acelerado pela desfolhação que afeta de maneira positiva na distribuição de luz, especialmente na região basal do dossel.

Os coeficientes de correlação de Pearson (r) só foram positivos e próximos a 1 (correlação forte) para as variáveis TAF e TPF em comparação a variável DPP, onde os valores de $\mathrm{r}$ foram, respectivamente, 0,80 e 0,76 . Os valores de $\mathrm{r}$ analisados para a variável altura foram negativos, apresentando correlação perfeitamente negativa. Os gráficos de correlação são apresentados a seguir:

Figura 03: Correlação entre taxa de produção de forragem (TPF) e densidade populacional de perfilhos (DPP).

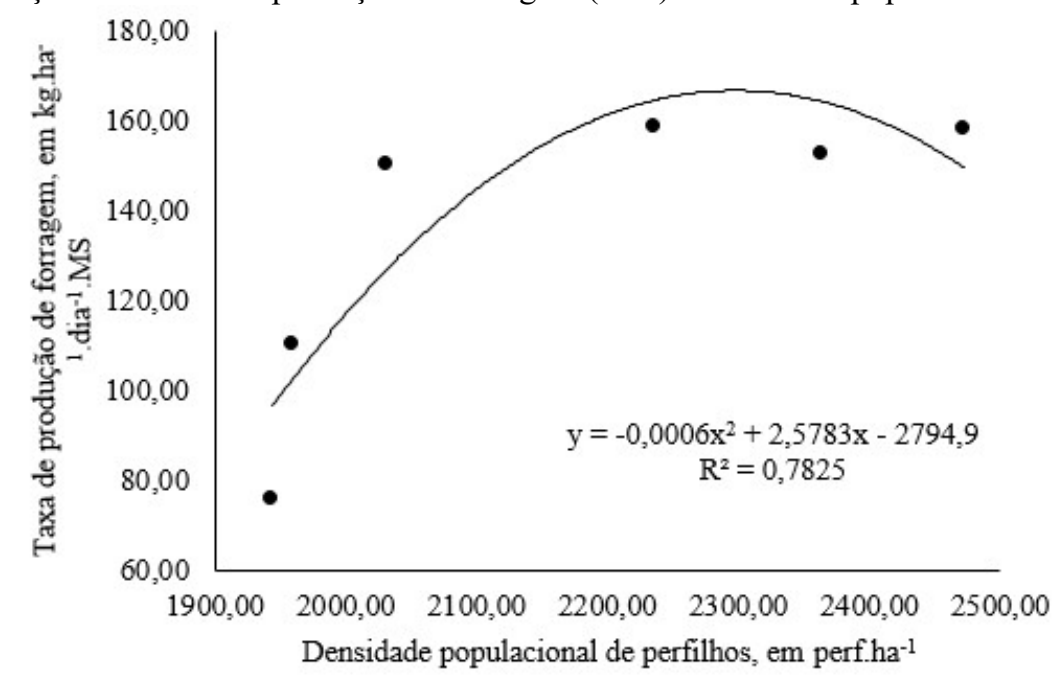

Fonte: Própria (2020). 


\section{ANÁLISES QUANTITATIVAS DO CAPIM-TAMANI}

Figura 04: Correlação entre taxa de acúmulo de forragem (TAF) e densidade populacional de perfilhos (DPP).

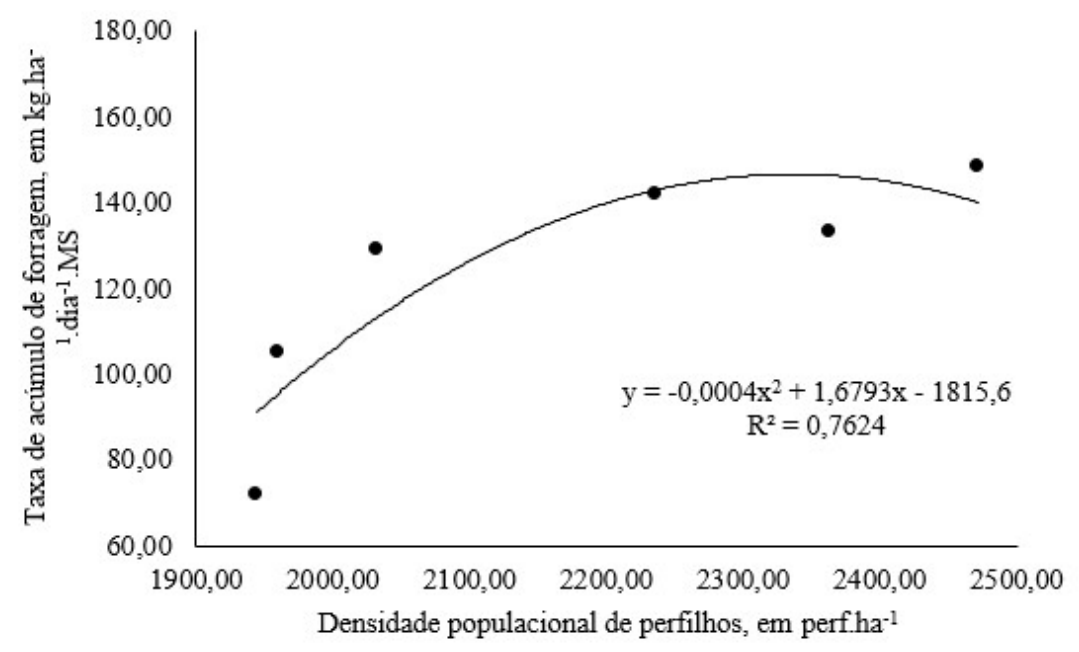

Fonte: Própria (2020).

Esses resultados indicam que o monitoramento através da variável DPP, avaliando a dinâmica de perfilhos do dossel, é mais indicado para estimar as taxas de acúmulo e de produção de forragem, quando comparado ao monitoramento através da variável $\mathrm{AD}$, em casos de manejos da adubação nitrogenada como estudados neste experimento.

\section{CONCLUSÕES}

A aplicação de fertilizante comercial de liberação controlada no tratamento Polyblen 1x (aplicação única) apresenta resultados estatisticamente iguais às aplicações parceladas para as variáveis TAF, TPF, AD e DPP em capim-tamani. Com base nesses resultados, recomenda-se a aplicação da ureia de liberação controlada em aplicação única.

As variáveis quantitativas, em especial a densidade populacional de perfilhos, ajudaram na avaliação da pastagem, permitindo observar as respostas da gramínea ao manejo que lhe foi empregado.

\section{REFERÊNCIAS}

ABIEC (São Paulo). Sumário ABIEC 2018. São Paulo: ABIEC, 2018. 49 p.

BARTHRAM, G. T. Sward structure and the depth of the grazed horizon. Grass and Forage Science, v. 36, p. 130-131, 1981.

CFSEMG. Comissão de Fertilidade do Solo do Estado de Minas Gerais. Recomendações para uso de corretivos e fertilizantes em Minas Gerais: quinta aproximação. Viçosa: UFV, 1999, $359 \mathrm{p}$.

CHAPIN, F. S.; BLOOM, A. J.; FIELD, C. B. WARING, R. H. Plant response to multiple 
environmental factors. Bio Science, v. 37, p. 49-57, 1987.

CORSI, M.; NUSSIO, L.G. Manejo do capim-elefante: correção e adubação do solo. In: SIMPÓSIO SOBRE MANEJO DE PASTAGENS, 10. 1992. Piracicaba. Anais... Piracicaba: FEALQ, 1992. p.87-116.

COSTA, K.A.P.; OLIVEIRA, I.P.; FAQUIM, V. et al. Produção de massa seca e nutrição nitrogenada de cultivares de brachiaria brizantha (a. Rich) stapf sob doses de nitrogênio. Ciência e Agrotecnologia, v.33, n.6, p.1578-1585, 2009.

COSTA, K.A.P.; OLIVEIRA, I.P.; SEVERIANO, E.C. et al. Extração de nutrientes pela fitomassa de cultivares de Brachiaria brizantha sob doses de nitrogênio. Ciência Animal Brasileira, v.11, n.2, 2010.

COSTA, N. de L.; PAULINO, V.T., MAGALHÃES, J.A., RODRIGUES, B.H.N.; SANTOS, F.D.S. Eficiência do nitrogênio, produção de forragem e morfogênese do capim-massai sob adubação. Embrapa Roraima-Artigo em periódico indexado (ALICE), 2016.

DA SILVA, S. C.; PEDREIRA, C. G. S. Princípios de ecologia aplicados ao manejo de pastagem. Simpósio sobre ecossistemas de pastagens, v. 3, p. 1-62, 1997.

DANCEY, C.P.; REIDY, J. Análise de correlação: or de Pearson. Dancey CP, Reidy J. Estatística sem matemática para psicologia. Porto Alegre: Artemed, p. 178-216, 2006.

DEBLITZ, C. Beef and Sheep Report: understanding agriculture worldwide. agri benchmark. 2012.

DIAS-FILHO, M.B. Diagnóstico das pastagens no Brasil. Embrapa Amazônia OrientalDocumentos (INFOTECA-E), 2014.

EMPRESA BRASILEIRA DE PESQUISA AGROPECUÁRIA - EMBRAPA - BRS Tamani, forrageira híbrida de Panicum maximum. Embrapa Gado de Corte. 2015.

EMPRESA BRASILEIRA DE PESQUISA AGROPECUÁRIA - EMBRAPA. Centro Nacional de Pesquisa de Solos. Sistema brasileiro de classificação de solos. 2. ed. - Rio de Janeiro: EMBRAPA-SPI, 2006. 306p.

FAO, STAT. Banco de dados FAOSTAT. Organização das Nações Unidas para a Alimentação e Agricultura, Roma, Itália , v. 1, 2013.

FIGUEIREDO FILHO, D.B.; SILVA JÚNIOR, J.A. Desvendando os Mistérios do Coeficiente de Correlação de Pearson (r). 2009.

GAO, X.; LI, C.; ZHANG, M.; WANG, R.; CHEN. B.; Controlled release urea improved the nitrogen use efficiency, yield and quality of potato (Solanum tuberosum L.) on silt loamy soil. Field Crops Research, v. 181, p. 60-68, 2015.

GAVALI, J. Estratégias de menejo do pasto para Panicum maximum cvs. Quênia e Tamani. 2016. 83 f. (Dissertação Universidade Federal do Mato Grosso). Mato Grosso. 2016.

GENG, J.; MA, Q.; CHEN, J.; ZHANG, M.; LI, C.; YANG, Y.; YANG, X.; ZHANG, W.; LIU, $Z$;; Effects of polymer coated urea and sulfur fertilization on yield, nitrogen use efficiency and 
leaf senescence of cotton. Field Crops Research, v. 187, p. 87-95, 2016.

GERLAND, P.; RAFTERY, A. E.; ŠEVČÍKOVÁ, H.; SPOORENBERG, T.; BAY, G. (2014). World population stabilization unlikely this century. Science, v. 346, n. 6206, p. 234$237,2014$.

GUARESCHI, R. F.; GAZOLLA, P. R.; PERIN, A.; SANTINI, J. M. K. Adubação antecipada na cultura da soja com superfosfato triplo e cloreto de potássio revestidos por polímeros. Ciência e Agrotecnologia, v. 35, n. 4, p. 643-648, 2011.

GUARESCHI, R.F.; PERIN, A.; GAZOLLA, P.R. Produtividade de milho submetido à aplicação de ureia revestida por polímeros. Global Science Technology, Rio Verde, v.6, n. 2, p. 31-37, 2013.

INMET - Instituto Nacional de Meteorologia. Banco de Dados Meteorológicos para Ensino e Pesquisa - BDMEP, 2020.

JANK, L.; BRAZ, T.G.S.; MARTUSCELLO, J.A. Gramíneas de clima tropical. In: REIS, R.A.; BERNARDES, T.F.; SIQUEIRA, G.R. (Eds). Forragicultura: Ciência, Tecnologia e Gestão dos Recursos Forrageiros. Jaboticabal, SP: Gráfica Multipress, 2013. p.109-119.

KOPPEN, W. das. Das geographische system der klimat. Handbuch der klimatologie, p. 46, 1936.

LACA, E.A.; UNGAR, E.D.; SELIGMAN, N.; DEMMENT, M.W. Effects of swardheight and bulk density on bitedimensions of cattlegrazing homogeneouss wards. Grass and forage Science, Oxford, v. 47, p.91-102, 1992.

LANA, R.M.Q.; SANTOS, C.M.; SANTOS, V.L.M.; BARBIZAN, E.L.; MENDES, A.F. Utilização de diferentes substratos e de fertilizantes de liberação lenta na produção de mudas do cafeeiro em sa $\neg$ quinhos. Revista Ceres, v.49, n.286, p.577-586, 2002.

LEMAIRE, G.; CHAPMAN, D. F. Tissueflows ingrazed plants communities. In: HODGSON, J., ILLIUS, A W. (Ed.). The ecology and management of grazing systems. Walling ford: CAB International, 1996. p. 3-36.

LOPES, M.N.; CÂNDIDO, M. J. D.; POMPEU, R. C. F. F.; DA SILVA, R. G.; DE LACERDA, C. F.; BEZERRA, F. M. L. Características morfogênicas de dois tipos de perfilhos e produção de biomassa do capim-massai adubado com nitrogênio durante o estabelecimento. Bioscience Journal, v. 30, n. 5, 2014.

MARTHA JUNIOR, G.B.; VILELA, L.; BARIONI, L.G.; SOUSA, D.M.G.; BARCELLOS, A.O. Manejo da adubação nitrogenada em pastagens. In: Simpósio Sobre Manejo da Pastagem, 21. 2004, Piracicaba. Anais... Piracicaba: Fundação de Estudos Agrários Luiz de Queiroz, 2004. p.155-216.

MARTUSCELLO, J.A.; SILVA, L.P.; CUNHA, D.D.N.F.V. Adubação nitrogenada em capimmassai: morfogênese e produção. Ciência Animal Brasileira, v.16, n.1, p.1-13, 2015.

MARTUSCELLO, J.A.; JANK, L.; FONSECA, D. M. D.; CRUZ, C. D.; CUNHA, D.D.N.F. V. Repetibilidade de caracteres agronômicos em Panicum maximum Jacq. Revista Brasileira de Zootecnia, v. 36, n. 6, p. 1975-1981, 2007. 
NABINGER. C.; PONTES, L. S. Morfogênese de plantas forrageiras e estrutura do pasto. In: Simpósio sobre a Produção Animal na Visão dos Brasileiros/Reunião da Sociedade Brasileira de Zootecnia, 38, 2001, Piracicaba. Anais... MATTOS, W. R. S. et al. (Ed.). Piracicaba: FEALQ, 2001.p. 755-771.

OKUMURA, R.S.; DE CINQUE MARIANO, D. Aspectos agronômicos da ureia tratada com inibidor de uréase, Ambiência, v. 8, n. 2, p. 403-414, 2012.

PARIS, W.; CECATO, U.; BRANCO, A.F. Produção de novilhas de corte em pastagem de Coastcross-1 consorciada com Arachispintoi com e sem adubação nitrogenada. Revista Brasileira de Zootecnia, v.38, n.1, p.122-129, 2009.

PEOPLES, M.B.; FRENEY, J.R.; MOSIER, A.R. Minimizing gaseous losses of nitrogen. In: BACON, P.E. (Ed). Nitrogen fertilization in the environment. New York: Marcel Dekker, 1995, chap. 15 p. 565-602RAIJ, B. van. Fertilidade do solo e adubação. Piracicaba: Ceres, 1991. $343 \mathrm{p}$.

PEREIRA, H. S.; LEÃO, A.F.; VERGINASSI, A.; CARNEIRO, M.A.C. Ammonia volatilization of urea in the out-of-season corn. Revista Brasileira de Ciência do Solo, v.33, p.1685-1694, 2009.

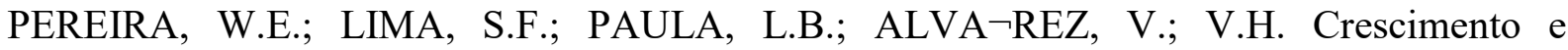
composição mineral de mudas de maracujazeiro em função de doses de osmocote em dois tipos de substratos. Revista Ceres, Viçosa, v.47, n.271, p.311-324, 2000.

PEREZ, A.A.G.; SORATTO, R.P.; MANZATTO, N.P. Extração e exportação de nutrientes pelo feijoeiro adubado com nitrogênio, em diferentes tempos de implantação do sistema plantio direto. Revista Brasileira de Ciência do Solo, v.37, p.1276-1287, 2013.

POMPEU, R. C. F. F.; CÂNDIDO, M. J. D.; LOPES, M. N.; GOMES, F. H. T.; LACERDA, C. F.; AQUINO, B. F.; MAGALHÃES, J. A. Características morfofisiológicas do capim-aruana sob diferentes doses de nitrogênio. Revista Brasileira de Saúde Produção Animal, v. 11, n. 4, p. 1187-1210, 2010.

POMPEU, R. C. F. F.; CÂNDIDO, M. J. D.; NEIVA, J. N. M. et al. Componentes da biomassa pré-pastejo e pós-pastejo de capim-tanzânia sob lotação rotativa com quatro níveis de suplementação concentrada. Revista Brasileira de Zootecnia. V, 37, n.3, p.383-393, 2008

PRIMAVESI, A.C.; PRIMAVESI, O.; CORRÊIA, L.A. Extração de nutrientes e recuperação aparente do nitrogênio pelo capim-coastcross adubado. Revista Ceres, v.51, n.295, p.295-306, 2004.

PRIMAVESI, O.; CORRÊA, L.A.; PRIMAVESI, A.C.; CANTARELLA, H.; ARMELIN, M.J.A.; SILVA, A.G.; FREITAS, A.R. Adubação com ureia em pastagens de Cynodon dactylon cv. coastcross sob manejo rotacionado: eficiência e perdas. São Carlos, SP: Embrapa Pecuária Sudeste, 2001. (Embrapa Pecuária Sudeste. Circular técnica, 30).

RODRIGUES, B.H.N.; MAGALHÃES, J.A.; LOPES, E.A. Irrigação e adubação nitrogenada em três gramíneas forrageiras no Meio-Norte do Brasil. Revista Ciência Agronômica, v.36, n.3, p. 274-278, 2005. 
SAS INSTITUTE. SAS System for Windows: version 9.0. Cary: SAS Institute Inc. 2003. 2 CD-ROMs.

SERRANO, L.A.L.; CATTANEO, L.F.; FERREGUETTI, G.A. Adubo de liberação lenta na produção de mudas de mamoeiro. Revista Brasileira de Fruticultura, v. 32, n. 3, p. 874-883, 2010.

SHAVIV, A. Advances in controlled-release fertilizers. Advances in Agronomy, San Diego, v. 71, n. 1, p. 1-49, 2001.

STOBBS, T. H. The effect of plant structure on the intake of tropical pastures. II. Differences in swards structure, nutritive value, and bite size of animal grazing Setaria anceps and Cloris gayana at various stages of growth. Australian Journal and Agriculture Resource, v. 24, n. 6, p. 821-829, 1973.

TESK, C.R.M.; RAMOS, T.A.; SCHMIDT JÚNIOR, R.J.; ARAGÃO, L.S.; CARAVALHO, P.de.; PEREIRA, D.H.; PINA, D.S.; PEDREIRA, B.C. Valor nutritivo dos capins Quênia e Tamani sob diferentes intensidades de desfolhação. In: SIMPOSIO MATO - GROSSENSE DE BOVINOCULTURA DE CORTE, 4. 2017, Cuiabá. Anais... Cuiabá: SIMBOV, 2017

TOMASZEWSKA, M.; JAROSIEWICZ, A.; KARAKULSKI, K. Physical and chemical characteristics of polymer coatings in CRF formulation. Desalination, Hopkinton, v.146, p.319-323, 2002.

VALENTIM, J.F.; CARNEIRO, J.da.C.; MOREIRA, P.; JANK, L. Capim-massai (Panicum maximum Jacq.): nova fronteira para diversificação das pastagens no Acre. Rio Branco: Embrapa Acre, 2001. 16 p. (Embrapa Acre. Circular técnica, 41).

VASCONCELOS, E.C.G. Morfofisiologia do capim-aruana pastejado por ovinos morada nova submetidos a quatro níveis de suplementação concentrada. 2014 . $70 \mathrm{f}$. Dissertação (mestrado em zootecnia)- Universidade Federal do Ceará, Fortaleza-CE, 2014.

VIANA, M.C.M.; FREIRE, F.M.; FERREIRA, J.J. Adubação nitrogenada na produção e composição química do capim braquiária sob pastejo rotacionado. Revista Brasileira de Zootecnia, v.40, n.7, p.1497-1503, 2011.

VILLALBA, H. A. G. Misturas de ureia revestida com polímeros e ureia convencional na adubação da cultura de milho. 2014. 91f. Dissertação (Mestrado) - Escola Superior de Agricultura "Luiz de Queiroz", Piracicaba, 2014.

VILLALBA, H. A. G. Misturas de ureia revestida com polímeros e ureia convencional na adubação da cultura de milho. 2014. 91f. Dissertação (Mestrado) - Escola Superior de Agricultura "Luiz de Queiroz”, Piracicaba, 2014.

VITOR, C.M.T.; FONSECA, D.M.da.; CÓSER, A.C. Produção de matéria seca e valor nutritivo de pastagem de capim-elefante sob irrigação e adubação nitrogenada. Revista Brasileira de Zootecnia, v.38, n.3, p.435-442, 2009.

YANG, Y.; ZHANG, M.; LI. Y.C.; GENG, Y. Controlled release urea improved nitrogen use efficiency, activities of leaf enzymes, and rice yield. Nutrient Management \& Soil \& Plant Analysis, v. 76, p. 2307-2317, 2012. 